\title{
Ageing and population shrinking: implications for sustainability in the urban century
}

\author{
Marcin Pawel Jarzebski (iD) ${ }^{1,2 凶}$, Thomas Elmqvist ${ }^{3}$, Alexandros Gasparatos (iD $^{4,5}$, Kensuke Fukushi ${ }^{4,5}$, Sofia Eckersten (iD $^{6}$, \\ Dagmar Haase iD $^{7,8}$, Julie Goodness ${ }^{9}$, Sara Khoshkar ${ }^{6}$, Osamu Saito (iD $^{10}$, Kazuhiko Takeuchi ${ }^{4,10}$, Töres Theorell ${ }^{11}$, Nannan Dong ${ }^{12}$, \\ Fumiko Kasuga ${ }^{2,13}$, Ryugo Watanabe ${ }^{14}$, Giles Bruno Sioen (D) $^{2,13}$, Makoto Yokohari ${ }^{15}$ and Jian $\mathrm{Pu}^{4}$
}

Population ageing and shrinking are demographic phenomena with far-reaching implications for sustainability in the current context of extensive and rapid urbanization. This Perspective rationalizes their interface by (a) identifying the challenges and opportunities that ageing and shrinking urban populations will have for implementing the sustainable development goals (SDGs), and (b) discussing some emerging interventions to capitalise on the opportunities and reduce the challenges to achieving sustainability. We argue that a diverse set of context-specific technological, socioeconomic, institutional and governance interventions would be needed to leverage effectively the opportunities and minimize the risks posed by ageing and shrinking urban populations for long-term sustainability.

npj Urban Sustainability (2021)1:17; https://doi.org/10.1038/s42949-021-00023-z

\section{INTRODUCTION}

In many regions of the world populations have grown older and fertility rates have declined to very low levels, leading to simultaneously shrinking and ageing populations ${ }^{1,2}$. Globally, people above 65 years old are the fastest-growing segments of the population and in 2019, for the first time in human history, they outnumbered children younger than 5 years old ${ }^{1,2}$. Population change, and especially population increase, has always been central to debates over sustainability ${ }^{3}$. For example, the UN Agenda 2030 was mostly discussed in the context of a rapidly growing global population, focusing on the strategies needed to achieve the sustainable development goals (SDGs) in view of the ever-increasing population pressures ${ }^{4}$.

Yet the far-reaching implications of ageing and population shrinking for sustainability have so far received limited attention in policy and practice. For example, the dimensions, dynamics and consequences of simultaneous ageing and shrinking populations are by and large overlooked in the SDG documents (SDGs), with ageing mostly visible only in relation to that older people are a vulnerable group ${ }^{5}$. In other highly visible UN documents related to sustainable development such as the New Urban Agenda, the challenges posed by ageing urban populations are mentioned in only one sentence ${ }^{6}$.

This pattern is also visible in the main strands of the academic literature relating to ageing and sustainability. In one strand, ageing is mostly discussed through the lens of labour markets economics, saving patterns, pension fund policies, and the provision of health and welfare services ${ }^{7}$. However, sustainability is not present in this literature in the conventional sense, considering the deeper discussion on the possible environmental consequences of ageing and shrinking populations ${ }^{8}$. Furthermore, many studies on the economic and social ramifications of ageing have focused either at the scale of the individual/single household (mainly studies from medicine and social science) or on the national scale (mainly studies from economics) ${ }^{7}$, missing to address the urban and regional scale.

Urban studies have been the second major academic strand bridging ageing and sustainability, mainly through the phenomena of ageing and shrinking cities. While the overall urbanization and extent of larger metropolitan areas are expected to increase in the foreseeable future in many regions ${ }^{9}$, other regions and cities are simultaneously showing striking signs of shrinking and ageing. For example, there are $\sim 350-400$ shrinking cities worldwide, most of them in Europe (especially its Eastern parts), Japan and the United States ${ }^{9-12}$. However, even though this literature has touched more on sustainability, it has been more through the lens of local aspects of planning, livability, and well-being, missing the larger sustainability ramifications of an ageing and shrinking urban population.

The above suggest that ageing and shrinking populations are usually perceived as challenging obstacles for meeting sustainability objectives, and rarely as opportunities. It is highly possible, however, that rapidly ageing and shrinking populations will have at the same time multiple positive and negative ramifications for sustainability in terms of economic growth, public sector development, consumption patterns, land use change, and greenhouse gas emissions, among others ${ }^{7,8}$. Thus they will most certainly also have important implications for the implementation of many of the SDGs.

This Perspective first makes the case that ageing and shrinking urban populations will pose both major challenges, but also provide opportunities for implementing the SDGs. Second, it argues that different context-specific emerging interventions would be needed to reduce the challenges and/or leverage the

\footnotetext{
${ }^{1}$ Tokyo College, University of Tokyo, Tokyo, Japan. ${ }^{2}$ Future Earth Global Hub, Tokyo, Japan. ${ }^{3}$ Stockholm Resilience Centre (SRC), Stockholm University, Stockholm, Sweden. ${ }^{4}$ Institute for Future Initiatives (IFI), University of Tokyo, Tokyo, Japan. ${ }^{5}$ Institute for the Advanced Study of Sustainability (UNU-IAS), United Nations University, Tokyo, Japan. ${ }^{6}$ Department of Sustainable Development, Environmental Science and Engineering, KTH Royal Institute of Technology, Stockholm, Sweden. ${ }^{7}$ Humboldt Universität zu Berlin, Berlin, Germany. ${ }^{8} \mathrm{Helmholtz}$ Centre for Environmental Research - UFZ, Leipzig, Germany. ${ }^{9}$ Law Faculty, University of Cape Town, Cape Town, South Africa. ${ }^{10}$ Institute for Global Environmental Strategies (IGES), Kanagawa, Japan. ${ }^{11}$ Department of Psychology, Stockholm University, Stockholm, Sweden. ${ }^{12}$ College of Architecture and Urban Planning (CAUP), Tongji University, Shanghai, China. ${ }^{13}$ National Institute for Environmental Studies (NIES), Tsukuba, Japan. ${ }^{14}$ Sado City Hall, Sado, Japan. ${ }^{15}$ Graduate School of Engineering, University of Tokyo, Tokyo, Japan. ${ }^{凶}$ email: jarzebski@tc.u-tokyo.ac.jp
} 
opportunities offered by ageing and population shrinking to enhance urban sustainability in this increasingly urban century. We note that ageing and shrinking populations are, from a demographic point of view, two separate phenomena. However, as they are often very tightly interconnected, we will explore their sustainability implications simultaneously. The first section provides an overview of the main global patterns of ageing and shrinking population in the context of urbanization. The second section focuses on the first part of the thesis, outlining the new challenges and opportunities for SDG implementation from ageing and shrinking urban populations. The third and fourth sections focus on the second part of the thesis, highlighting some of the possible emerging interventions for reducing the challenges and/or leveraging the opportunities offered by ageing and shrinking populations, and well potential risks ahead.

\section{INTERFACE OF AGEING, POPULATION SHRINKING AND URBANIZATION}

In 2020, 9\% of the global population was above 65 years old, accounting for 728 million people. This population is projected to increase more than twofold, reaching 1.55 billion in 2050 and accounting to $16 \%$ of global population, at medium fertility rates ${ }^{1}$. People above 80 years old accounted for 143 million in 2019, and are expected to reach 426 million in 2050 and account for nearly $60 \%$ of the elderly population ${ }^{1}$, increasing particularly fast in highincome countries (Supplementary Fig. 1). However, there are major regional discrepancies in current and future patterns of ageing, with Europe expected to remain the most aged society in 2050, Asia experiencing large increases in aged population (especially in China), and most countries in Africa having a mostly young population ${ }^{1}$ (Fig. 1) (see Supplementary Table 1 for examples from selected countries). Regardless of these trends, in both affluent and less affluent regions, older women generally greatly outnumber older men, with the oldest age groups in some regions being completely female ${ }^{5,9}$.

At the same time, there are major changes in fertility rates and population sizes. Currently, fertility rates are near or below the 2.1 replacement level in all regions apart from the African continent, and are expected to continue decreasing well below this replacement level in most regions except Africa in $2050^{1}$. Out of the 27 countries with the lowest fertility rate under 1.5 globally in 2018, 21 are in Europe or East Asia (Supplementary Fig. 2). Similarly, many countries and regions are expecting large population shrinking by 2050, with most of these countries located in Europe and Asia (Fig. 2) (see Supplementary Table 1 for examples from selected countries). Some of the current fertility, mortality, migration, and population models suggest that the UN figures can be still vastly underestimated ${ }^{13}$.

The above suggest the strong relationships between ageing patterns with fertility rates and population shrinking, which collectively represent a major demographic transition. This demographic transition seems to be currently mainly confined to Europe and East Asia as outlined above (Figs. 1 and 2). However, it is important to note that there may be strong interactions in that increases in the proportion of elderly in a country can put more economic and social pressure on working age population, further decreasing birth rates and/or postponing child births, thus driving fertility rates even lower ${ }^{14}$.

Before delving into the implications of an ageing and shrinking urban population for sustainability in the next section, it is important to understand the role of urbanization in this demographic transition, and the characteristics of ageing urban populations. Urbanization reportedly plays a major role in this interface, as it is a multi-dimensional process associated with increased affluence and access to jobs, improved health care and education, and cultural and behavioural change ${ }^{14}$. While initially urbanization may be partly driving mortality rates down due to increased affluence and access to health care, it later on may lead to women taking stronger control of their lives resulting in declining fertility rates (Fig. 3$)^{14}$. However there is great variability in the relationship between fertility decline and urbanization between regions (Fig. 4). For example, low-income countries are often characterized by a steep decline in fertility rates with increases in urbanization, but the pattern may vary regionally (Supplementary Fig. 3). At the same time, livelihoods in urban areas are seldom dependent on adding members to the family, in contrast to many rural areas ${ }^{15}$. Instead, adding children may increase living costs and put constraints upon the often very mobile and career-oriented (yet underpaid) life of urban women ${ }^{16}$. It is worth mentioning that variation between countries may also be due to the different metrics and cut-offs levels for measuring urbanization, and a multitude of local and context-specific factors that in turn may influence variables underlying fertility rates, such as health, education, income and gender equality ${ }^{17}$. In any case irrespective of this variation, urbanization as a complex variable still seems to reasonably capture in an aggregate way the important mechanisms underlying declining fertility rates ${ }^{18}$.

Finally, it is worth noting that many of these demographic transitions are made within the context of accelerating climate change. Climate change can and will intersect with these demographic changes in multiple ways. For example, it can impact fertility by changing human behaviour and affecting migration patterns within countries (e.g. from rural to urban areas) and between countries (e.g. from poor to rich countries) ${ }^{19}$. These climate change-related shifts in migration patterns can exacerbate ongoing population shrinking and ageing, for example by influencing younger people to out-migrate from already rapidly ageing areas, accelerating thus population shrinking in some areas ${ }^{13,20,21}$.

\section{SUSTAINABILITY CHALLENGES AND OPPORTUNITIES Interface of ageing and sustainability}

First, older populations experience specific challenges related to access to health, safety, capacity to deal with disasters, vulnerability to diseases/pandemics, and mobility, among others ${ }^{5,22}$. Such challenges increase the vulnerability of the elderly and require particular interventions ${ }^{23}$. The recent COVID-19 pandemic showed clearly many of these weaknesses for the elderly ${ }^{24}$. This implies some of the many challenges that an ageing population can pose for meeting many of the SDGs and their underlying targets.

Second, in the last few decades there have been significant changes in the health status and risks, activity and productivity patterns, and the socioeconomic characteristics of the elderly ${ }^{2}$. On the one hand, this has led to the development of alternative concepts and measures to offer a more nuanced perspective of what population ageing means in different contexts. This includes, for example, measures based on prospective age (i.e. years of life remaining), with a dynamic threshold of 'old age' that rises progressively with increasing life expectancy and health at old age, point toward a slower process of population ageing than what is indicated by the conventional measures ${ }^{25}$. Such measures can have significant implications for assessing the living conditions and living arrangements of older persons, their productive, experiencebased and other contributions to society and their needs for social integration and health care. On the other hand, these shifts in the characteristics and capabilities of the elderly populations can offer real opportunities for meeting some SDG targets.

Third, although UN population projections are made at the country level ${ }^{1}$, cities represent both those areas where most elderly people will live in the near future and an arena, where the recent demographic transitions have unfolded and the new ones will emerge ${ }^{26}$. Thus an urban perspective is necessary when identifying the sustainability challenges and opportunities 

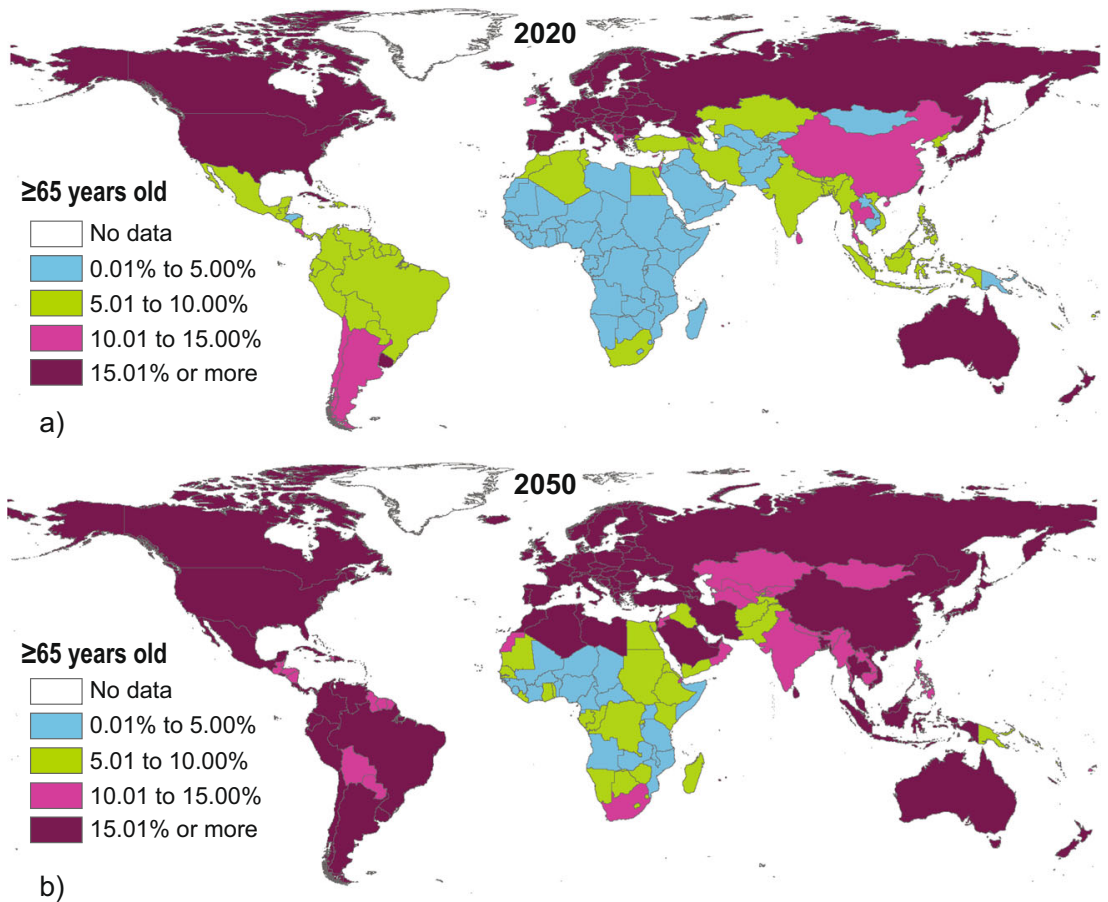

b)

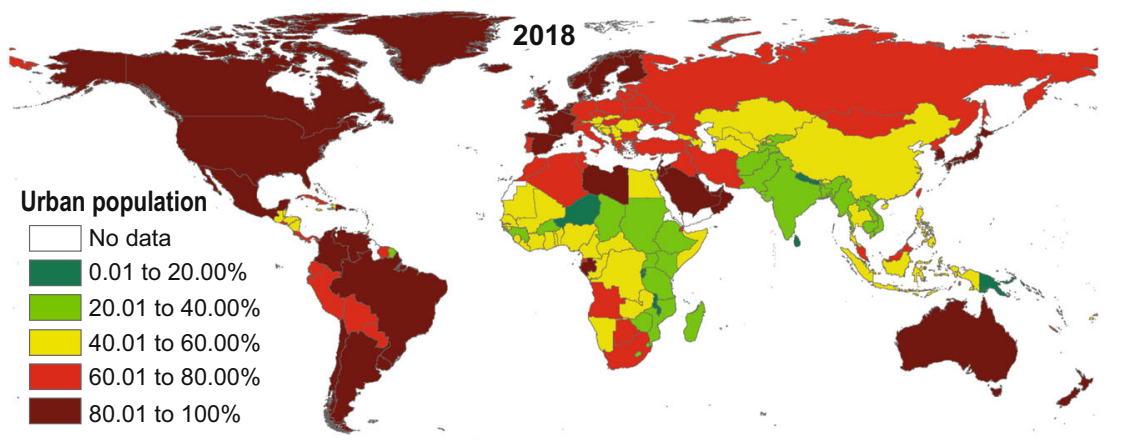

c)

Fig. 1 Proportion of aged population (in 2020 and 2050) and urban population (in 2018). Note: For $a$ and $b$ the projected fractions of the population above 65 years old (in \%) is based on the UN medium variant ${ }^{1}$. For $\mathbf{b}$ the proportion of urban population (in \%) is based on ${ }^{114}$.

emerging through the demographic transition posed by an ageing and shrinking population.

The three following sub-sections explore in more depth how the ageing and shrinking populations may offer new opportunities or challenges in achieving the SDGs. We focus on 12 SDGs for which there is currently the clearest evidence to support this discussion in the context of ageing and shrinking population. We divide these SDGs across the three thematic categories of biosphere, society and economy ${ }^{27}$.

\section{Biosphere-related SDGs}

Ageing and shrinking populations are expected to offer major opportunities to achieve some targets associated with SDG6 (Clean Water and Sanitation), SDG14 (Life under Water) and SDG15 (Life on Land), and both opportunities and challenges to meet SDG13 (Climate Action), as discussed below.

Many studies have argued that ageing and shrinking populations will be beneficial for biodiversity conservation and ecosystem functioning (see an extended review in ref. ${ }^{8}$ ). This is mainly through reduced environmental pressures from decreases in total consumption, considering that the growth of human population and consumption are both major drivers of global environmental change ${ }^{28-31}$. These possibly lower consumption rates associated with smaller and older populations ${ }^{32,33}$ could reduce pressures to convert natural areas for agriculture or alter rivers to provide water for agriculture and growing cities ${ }^{8}$. For example, the projected population shrinking in Japan will possibly reduce pressure on land, opening possibilities for rewilding land that is no longer needed for agriculture, forestry, or other intensive human uses ${ }^{34}$. However, this might not be transferable and/or might differ among countries. The above offer real opportunities for meeting SDG targets such as 15.1 (conservation, restoration and sustainable use of terrestrial and inland freshwater ecosystems and their services), 6.1 (universal and equitable access to safe and affordable drinking water), or 14.4 (regulate harvesting and end overfishing, illegal, unreported and unregulated fishing and destructive fishing).

However, ageing will create constraints for meeting SDG13 and particularly target 13.1 (resilience and adaptive capacity to climaterelated hazards and natural disasters), considering that the elderly are generally more vulnerable to climatic extremes and disasters through diverse mechanisms $\mathrm{s}^{35}$. For example, the elderly are more vulnerable (and less able to adapt) to disasters such as floods, landslides, and typhoons due to mobility or connectivity constraints $^{36-39}$. Furthermore, they are more vulnerable to heat ${ }^{40}$, with 


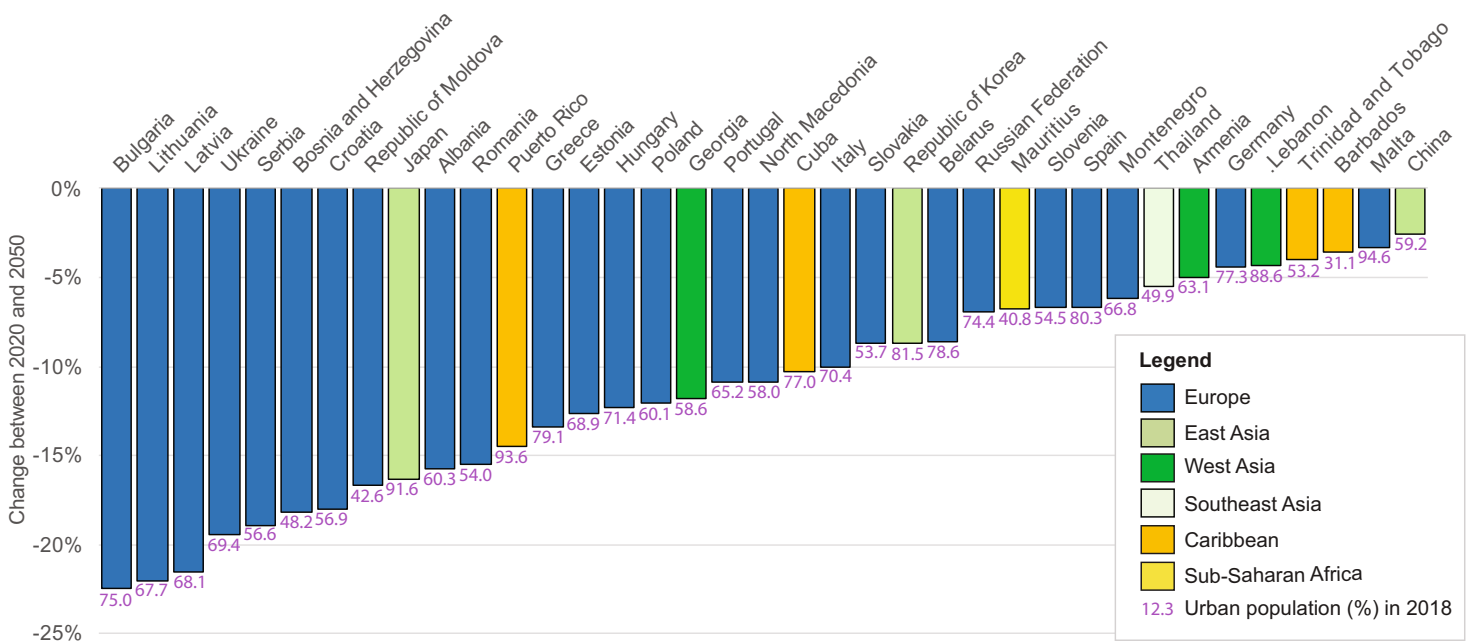

Fig. 2 Countries with the highest projected population shrinking by 2050 . Note: The bars denote the projected fraction of population shrinking between 2020 and 2050 (in \%) (Data source: '); The purple figures denote the fraction of the urban population in 2018 (in \%) (Data source: ${ }^{114}$ ).

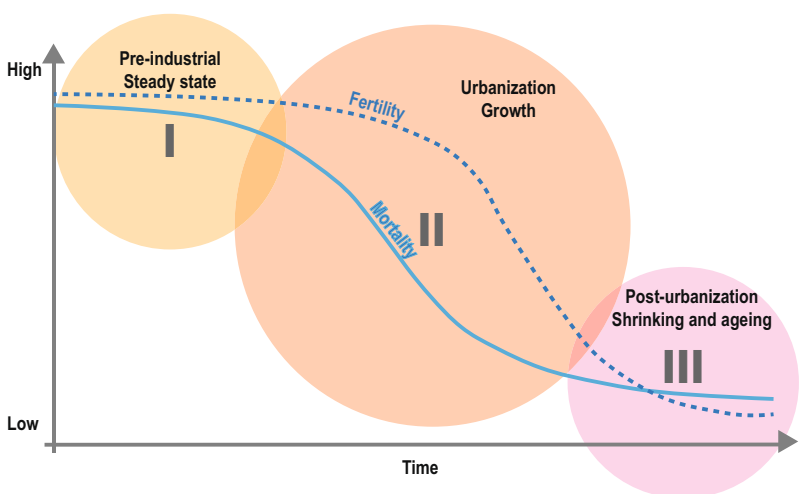

Fig. 3 Evolution of the relative levels of mortality and fertility rates over time. Note: Based on ${ }^{14}$.

heat waves causing the highest death tolls to people over 65 years old $^{41}$. The expected increases in the frequency and magnitude of climatic disaster will most likely increase the vulnerability of ageing societies, e.g. many European and Asian countries characterized by an ageing population will become highly or very highly vulnerable to heatwaves (Supplementary Fig. 4). Interestingly ageing and population shrinking can have rather variable effects for GHG emissions, and thus climate change mitigation efforts. For example, population shrinking can provide $16-29 \%$ of the emission reductions needed by 2050 to keep average global temperature increases below $2{ }^{\circ} \mathrm{C}$, and as much $37-41 \%$ of necessary emission reduction by the end of the century ${ }^{42}$. Furthermore, ageing populations provide a potential for further emission reductions due to declining age-specific material consumption at older ages ${ }^{32}$. Although there are sector, timing, and scale-effect discrepancies, it is expected that in the long run population ageing would reduce overall emissions $33,43,44$. However, some studies have found that elder age groups can have higher carbon footprints compared to younger age groups, due to emission-intensive activities, such as higher personal car use, home heating and medical care and treatment $^{45-47}$.

\section{Society-related SDGs}

An ageing and shrinking population will pose major challenges for meeting SDG3 (Good Health and Wellbeing). Further to the absence of disease, healthy ageing would also require the maintenance of functional ability throughout a person's lifespan. As mentioned in the previous sub-section the elderly are more vulnerable to environmental stressors and disasters. Similarly, water-borne diseases such as norovirus, and epidemics such as the recent COVID-19 virus or recurring influenza outbreaks are especially dangerous to the elderly ${ }^{48,49}$. Thus, health and longterm care systems need to be able to meet the needs of ageing populations through appropriate integrated care and maintaining the intrinsic capacity of older persons. However, there is ample literature on the health care-related challenges connected to an ageing society, including the escalating costs in terms of care and medicine, and the lower ability of shrinking populations to meet $^{7,50}$. The above suggest that ageing will pose challenges for Target 3.4 (reduce premature mortality from non-communicable diseases) and 3.8 (universal health coverage, including financial risk protection, access to quality essential health-care services and access to safe, effective, quality and affordable essential medicines and vaccines), with the latter possibly exacerbated by population shrinking.

Similarly ageing will most likely reinforce old (and create new) inequalities ${ }^{51}$, which will pose challenges for meeting SDG1 (No Poverty), and especially the targets on poverty levels (Target 1.1-1.2) and social protection (Targets 1.3-1.4). In particular elderly people have a lower participation in employment and in most cases rely solely on pensions, with a substantial fraction of elderly falling below the poverty lines in their respective countries as pensions are not always enough to cover their daily needs ${ }^{5,52,53}$. Similarly in many of the rapidly ageing societies (especially in eastern Asia), the existing social protection programmes are not sufficiently strong and comprehensive to cover the needs of the increasingly elderly population (let alone a rapidly increasing one) with fewer people of working age contributing to them ${ }^{51-53}$. It is worth noting that there is a persistent gender gap in both the coverage and absolute levels of pensions ${ }^{52}$, which suggests also major implications for SDG5 (Gender Equality). However, the actual effects of inequalities in pension levels and coverage might be a bit more difficult to delineate for meeting SDG5.

Conversely, an ageing and shrinking population can offer both opportunities and challenges for meeting SDG2 (Zero Hunger). For example, theoretically speaking a shrinking population will require a lower amount of food, with this lower consumption reducing pressure on the food system and improving food security (see the previous sub-section). However, lower incomes for the elderly (see SDG1), might not allow the sufficient food access for all, as has 


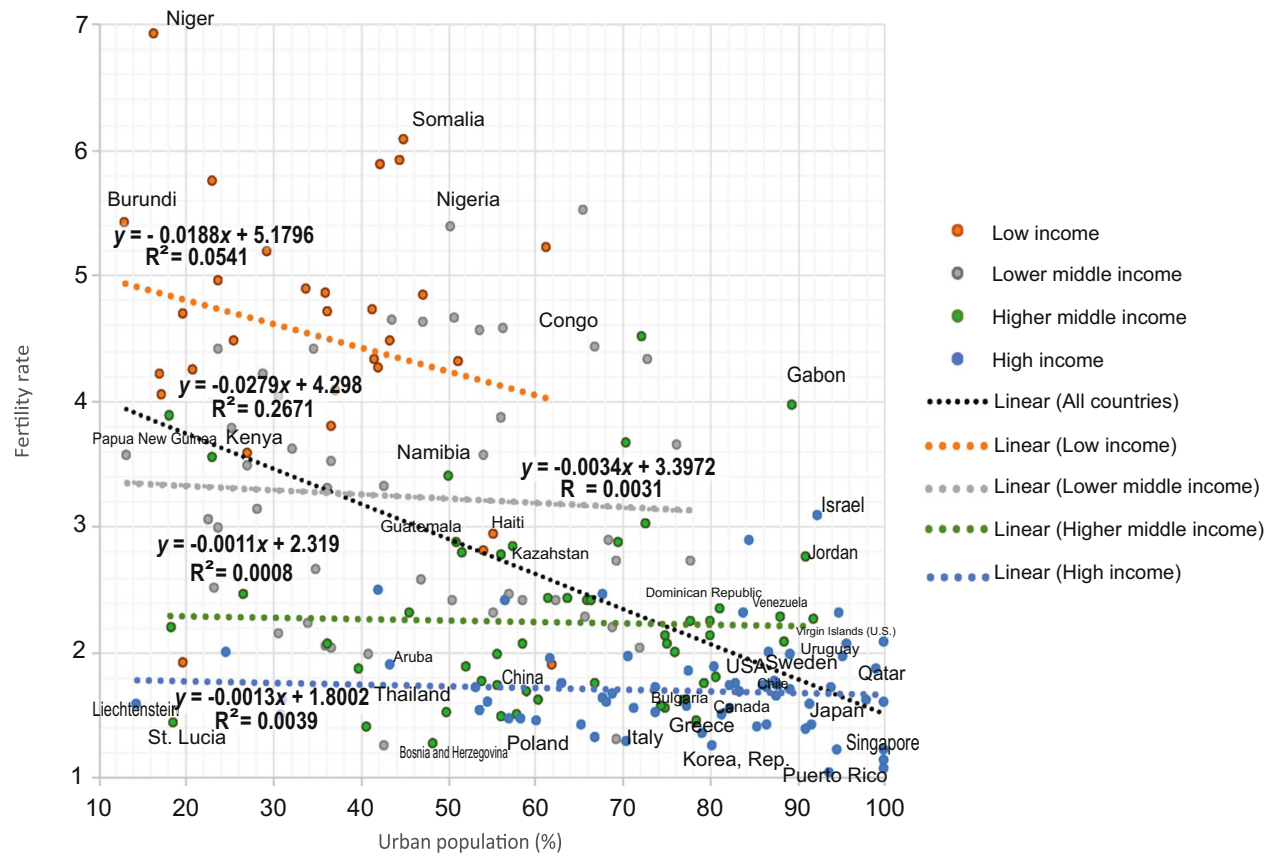

Fig. 4 Fertility rates and urban population fraction in 2018. Note: Data source: ${ }^{1,114}$.

been shown for elderly people $e^{54,55}$. Furthermore, an ageing and shrinking population might have an adverse effect on agricultural production due to the shrinking workforce in the agricultural sector (as has been observed in many ageing societies) ${ }^{56}$, but such effects might be offset partly or completely through automation $^{57}$. Another possible challenge might emerge from the loss of traditional agricultural practices, local agricultural knowledge and local varieties, which has been observed in many ageing and shrinking communities, characterized by lower employment in agriculture. The above suggest that ageing and shrinking populations might pose challenges for meeting target 2.5 (maintain genetic diversity of crops), opportunities for target 2.4 (ensure sustainable food production systems and resilient agricultural practices), but possibly less clear outcomes for target 2.1 (end hunger and ensure access to food) and 2.3 (double the agricultural productivity and incomes of small-scale food producers).

Similarly, an ageing and shrinking population can offer both opportunities and challenges for SDG11 (Sustainable Cities and Communities). On the one hand, shrinking populations would ease up pressure on housing markets and make it easier to access affordable housing in urban areas. However, there is a need to be mindful of socioeconomic and sociospatial inequalities, and the challenges they might pose ${ }^{58}$. On the other hand, older people spend comparatively more of their time at home, which makes housing an important component of age-friendly cities ${ }^{59,60}$. Evidence suggests that many existing homes are not suitable for the varied needs of older people ${ }^{61-63}$. With most existing housing stock likely to be still in use by 2050 in ageing regions such as Europe, many homes will need to be adapted so that older people can continue to live in them ${ }^{59}$. Thus an ageing and shrinking population offers both challenges and opportunities for meeting target 11.1 (access to adequate, safe and affordable housing and basic services and upgraded slums).

An ageing population would most likely increase policy demand for designing accessible and safe public spaces (see the section "Boost innovation for health care and mobility"), which will have major implications for Target 11.7 (universal access to safe, inclusive and accessible, green and public spaces). On the one hand, green spaces can promote physical activity and improve the physical and mental health among older people ${ }^{64,65}$, paying clear dividends for other SDGs (see the section "Boost innovation for health care and mobility"). However, there are many barriers preventing older people from using green spaces, for example due to safety concerns ${ }^{66}$ or their design that often prioritizes other users (e.g. children). At the same a shrinking urban population might reduce the available financial resources for developing and maintaining age-friendly public spaces (e.g. through municipal taxes ${ }^{67}$, putting an extra challenge for meeting target 11.7 .

Similarly ageing and shrinking populations would make a strong case for reconfiguration and added investments in public transport ${ }^{26}$, but at the same time increase the risk of declining revenues and reducing public transport service provision where elderly fares are subsidized. Similar to public spaces, if transport services cannot meet the mobility needs of the elderly, there is a high risk of social isolation or depressive symptoms ${ }^{68,69}$. Similar to the above a possible decline in available financial resources might challenge the development of age-friendly transport systems. The combined effect of the above would pose a major challenge for addressing target 11.2 (access to safe, affordable, accessible and sustainable transport systems...notably by expanding public transport).

Finally due to the expected reduction in material consumption ageing and shrinking populations can offer real opportunities for meeting Target 11.6 (reduce the adverse per capita environmental impact of cities). However, as also mentioned in some cases elder populations have a higher carbon footprint for some categories, which might pose some barriers (see the previous sub-section).

\section{Economy-related SDGs}

Overall it is expected that an ageing and shrinking population will pose challenges for achieving SDG8 (Decent Work and Economic Growth) and SDG9 (Industry, Innovation and Infrastructure). The major mechanism relates to the declining and comparatively lower number of young workers and taxpayers ${ }^{7}$. The dependency ratio is often used as a measure of societal capacity for economic growth, with a declining dependency ratio implying that the burden on the working segment of the population increases, creating fiscal pressures on developing and maintaining public health care, pension, infrastructure, and social protection systems for older 


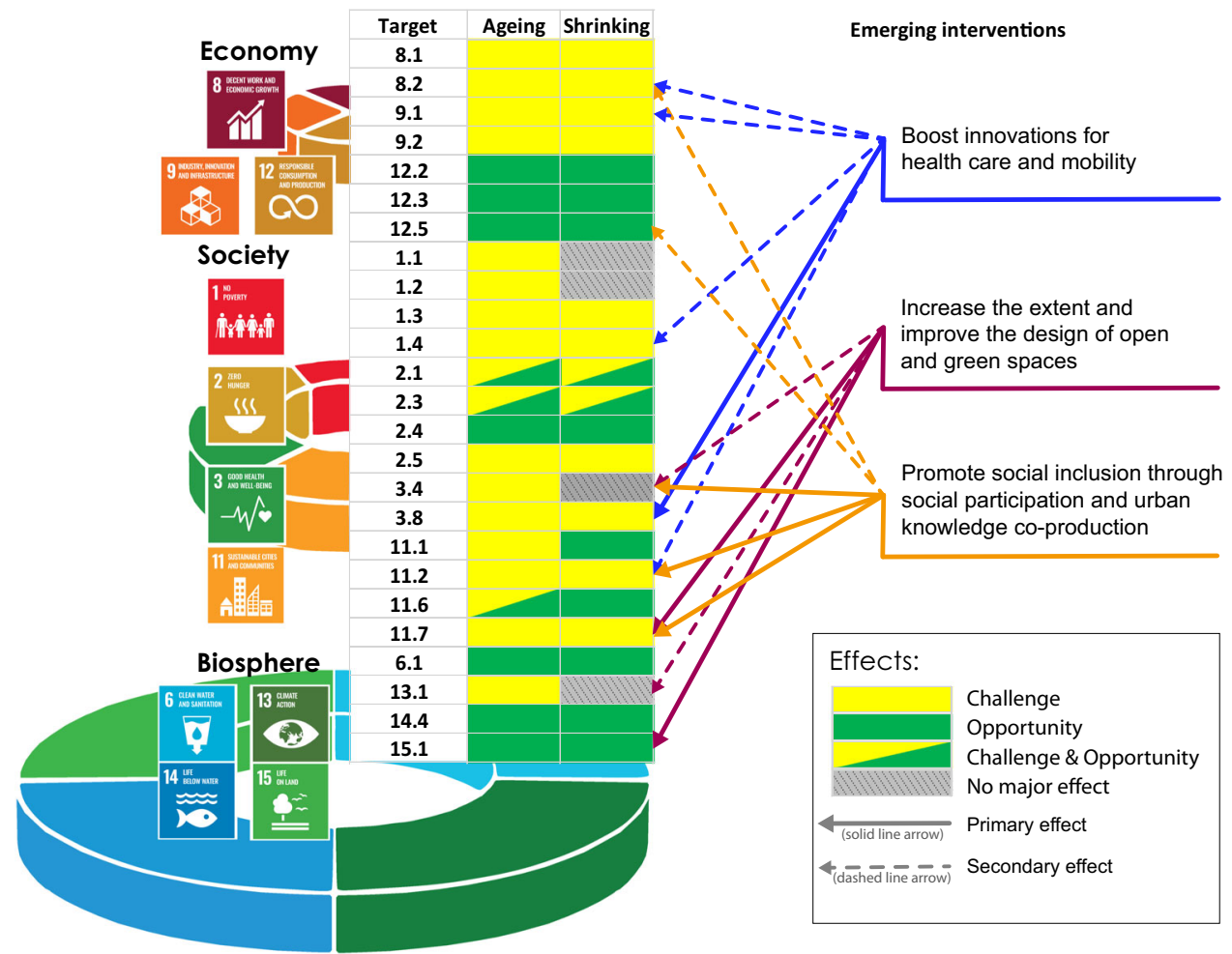

Fig. 5 Potential effects of population ageing and shrinking for selected SDG targets and the contribution of emerging interventions. Note: The division of SDGs across the three thematic categories is based on ${ }^{27}$.

persons ${ }^{7}$. For reference, currently Japan has the lowest dependency ratio in the world (1.8), and by 2050 more than 48 countries are expected to have ratios below $2^{1}$. Considering this situation it is widely believed that productivity can only be boosted through increased innovation and automation in all sectors of society (e.g. robots replacing workers in manufacturing, health and elder care centres). However, there are strong reasons to believe that rates of innovation may decrease in ageing societies, and thus slow down further economic growth and workforce replacement ${ }^{70}$. The above suggest that ageing and shrinking populations will pose major challenges for meeting many individual targets such as Target 8.1 (sustainable economic growth), 8.2 (diversify, innovate and upgrade for economic productivity), 9.1 (sustainable, resilient and inclusive infrastructures), and 9.2 (inclusive and sustainable industrialization), among others.

Conversely, ageing and shrinking populations might provide opportunities for achieving SDG12 (Sustainable Production and Consumption). The key entry point are the forecasted lower levels of consumption from both an ageing and shrinking population (see the section "Biosphere-related SDGs"), which is expected to provide opportunities for Targets 12.2 (sustainable management and efficient use of natural resources), 12.3 (halve per capita global food waste....and reduce food losses along production and supply chains), and 12.5 (reduce waste generation through prevention, reduction, recycling and reuse $)^{71}$.

\section{EMERGING INTERVENTIONS}

\section{Capitalize on opportunities and reduce challenges}

As the previous section has outlined, population ageing and shrinking both pose challenges and offer opportunities for meeting a very diverse set of SDG targets (Fig. 5). We argue that in order to enhance sustainability there is a real need to put in place interventions or strengthen existing processes in order to capitalize effectively on the new opportunities and reduce the new challenges posed by ageing and shrinking populations. Arguably many of the interventions will be context-specific considering the major differences between countries (and areas within individual countries) in terms of the pace of ageing and shrinking (see the section "Interface of ageing, population shrinking and urbanization"), the socioeconomic and environmental conditions, and the ability to invest resources.

In our opinion three very different, but also very promising, emerging interventions discussed in the following sub-sections are to (a) boost innovation for health care and mobility, (b) increase the extent and improve the design of open and green spaces, (c) promote social inclusion through social participation and urban knowledge co-production.

While we acknowledge that these are only some of the possible emerging interventions, we believe that they offer a good crosssection of possible options. This is because they span very different domains (e.g. technology adoption, social innovation, urban planning), target very different SDG targets through different mechanisms (Fig. 5), and are amenable and transferable to different geographical contexts, environmental and socioeconomic conditions and abilities to invest resources.

\section{Boost innovation for health care and mobility}

Many emerging interventions seek to improve health care and mobility have been piloted or implemented across countries/ cities experiencing an onset in population ageing and/or shrinking (Fig. 5). These interventions range from technological innovations, to social and institutional innovations.

Some of the technological innovations for health care include socially assistive robots and virtual entertainment for mental health ${ }^{72,73}$, roadside Al services for healthcare, and a series of innovations for house-based healthcare, digital nursing and monitoring $^{74}$ (Supplementary Table 2). More conventional approaches include, among others, care homes that bring together young and older people, volunteering in care homes, 
and day-care houses to occupy the elderly during the day (Supplementary Table 2).

Urban mobility plays an important role for the effective social inclusion of the elderly, and can include both conventional and innovative approaches. Central to these approaches would be to harness the potential offered by new patterns of urban mobility provision, which has been moving towards the concept of Mobility as a Service (MaaS) through the use of smartphones and ubiquitous internet connection, and the combination of transportation services from public and private providers ${ }^{75}$. It has been argued that MaaS could contribute to a better accessibility for the older population, given that they learn how to use the necessary technological interventions (i.e. smart phones) ${ }^{76}$.

This can be combined with age-friendly transport interventions including special fares, reduced barriers in transport hubs, and age-friendly vehicle functionalities (Supplementary Table 2), as well as active travel options such as e-bikes ${ }^{77}$. Other innovations that can improve mobility in the context of ageing and shrinking societies include autonomous driving, with different possible modes offering different advantages and disadvantages ${ }^{78}$.

\section{Increase the extent and improve the design of green spaces}

There is a strong evidence-base to suggest that public and green spaces (including urban agriculture) can have ripple positive outcomes for the physical, mental and psychological health of urban residents (Fig. 5) ${ }^{79-81}$. Green spaces can promote physical activity among older people, with cross-sectional surveys linking the engagement with (and quality of) open spaces to the increased life satisfaction, and reduced loneliness and social isolation of the elderly ${ }^{64,65}$. Green spaces have also played a crucial role as familiar escapes during the recent COVID-19 pandemic and other hazards.

Population ageing and shrinking open up numerous possibilities for new approaches to increase the extent and improve the design of green spaces, and open spaces more generally. Such approaches would need to put more emphasis on the multifunctionality of the urban landscape and create synergies among different age groups ${ }^{82-84}$.

At the level of the individual green or public space, new urban designs must consider principles of inclusivity to ensure both the accessibility/safety of the elderly, as well as integrate elements/ functionalities that would increase their satisfaction (e.g. walking path routes, seating, plant species) ${ }^{85}$. Furthermore, green/public areas would need to be closer to residential homes and consider issues of social connection and mobility (see also the previous sub-section) ${ }^{86,87}$.

At the level of the neighbourhood or the city, many different planning approaches have been suggested that reflect and emphasize on different urban and cultural socioeconomic characteristics $^{82,83}$. For example, the compact city approach is one potential intervention that has been applied in various countries for sustainable growth ${ }^{88}$, but has also been used in some ageing and shrinking cities to control further shrinkage ${ }^{89}$. The Compact City approach seeks to (a) transform low density urban land uses into green/spaces and prohibit urban development, (b) promote densification of the urban centres with convenient nodes for transportation, and (c) develop new housing and rebuilds aged infrastructure in designated zones ${ }^{90}$. This approach plans for the gradual urban shrinking by transforming one vacant lot at a time ${ }^{89}$, which requires long time-term thinking and transient or temporary green spaces (e.g. woodlands, urban agriculture $)^{91,92}$. However, we should also note some of the possible negative feedbacks between densification and liveability for older people, such as through exacerbating urban heat island effect $^{93}$, unsuitable housing ${ }^{94}$ or gentrification ${ }^{95}$. Such factors would need to be considered when reconfiguring urban spaces in order to ensure sustainability in the context of ageing and shrinking urban populations.

In this context climate change considerations would need to be factored in urban green designs to ensure that they provide both adaptation and mitigation services to urban populations ${ }^{96,97}$. Some examples can be storm water collection in urban farms during intense rainfalls to avoid hygiene issues ${ }^{98}$, or trees providing shade that gives a cooling effect during extreme heat to reduce chances of heat stress ${ }^{99}$. This becomes particularly important considering both the increased vulnerability of elderly (see the section "Society-related SDGs"), as well as their different capacity to employ (and preference for) related coping strategies $^{100}$. In this sense, investing in green infrastructure (and included green spaces) that caters to the elderly through multiple ecosystem services should be seen as a future planning priority in rapidly ageing urban contexts ${ }^{101}$.

\section{Improve social inclusion}

An ageing population presents a large untapped potential for sustainable development (Fig. 5). Specifically under appropriate conditions this growing population of skilled, increasingly healthy and active people, with lots of spare time can engage in various sustainability initiatives at the local level. There has been demonstrated interest of older people in many countries to continue working or they volunteer in their communities, the extent to which older people participate in the social, civic and economic life of the city is closely linked to their experience of inclusion ${ }^{66}$.

Some suggestions to facilitate social participation are to enhance the availability and variety of social activities closer to elderly residents and foster integration within the community and with other age groups and cultures ${ }^{66}$. Accordingly, communities should facilitate for elderly residents to choose among and to participate in cultural activities-such as music and dance, which have demonstrated physical and mental health benefits ${ }^{102}$.

Urban co-production processes, such as those reflected in SDG Target 11.3 (inclusive and sustainable urbanization and capacity for participatory, integrated and sustainable human settlement planning and management) that entail the engagement of multiple stakeholders to produce research and knowledge outputs to solve urban problems ${ }^{103}$, provide an excellent opportunity to involve meaningfully older citizens and incorporate their perspectives on urban sustainability challenges, including those affecting them directly, e.g. planning of city transportation systems, housing, and outdoor spaces ${ }^{104-106}$. While challenges exist to establishing and implementing co-production processes with older people ${ }^{107}$, evidence for successful examples is emerging ${ }^{108}$.

\section{AVOID VULNERABLE STATES FROM COORDINATED MITIGATION ACTIONS}

Considering the multi-dimensional nature of population ageing and shrinking, and the high context-specificity of the observed patterns across the world, it is expected that broad mitigation efforts would be needed by national and local governments to ensure the successful implementation of the SDGs. For example this would most likely need the implementation of emerging interventions such as the one discussed in the previous section, and broader policies that seek to prevent macroeconomic decline ${ }^{2}$ such as to (a) increase in retirement age; (b) support continuing and lifelong education and health care for all; (c) encourage savings behaviour and healthy lifestyles throughout the life course; (d) promote employment among women, older persons and others traditionally excluded from the labour force; (e) support family-friendly policies to facilitate work-life balance and increased gender equality in both public and private life ${ }^{2,52}$.

In this sense, different ageing and shrinking countries and regions will very likely adapt through various context-specific social 


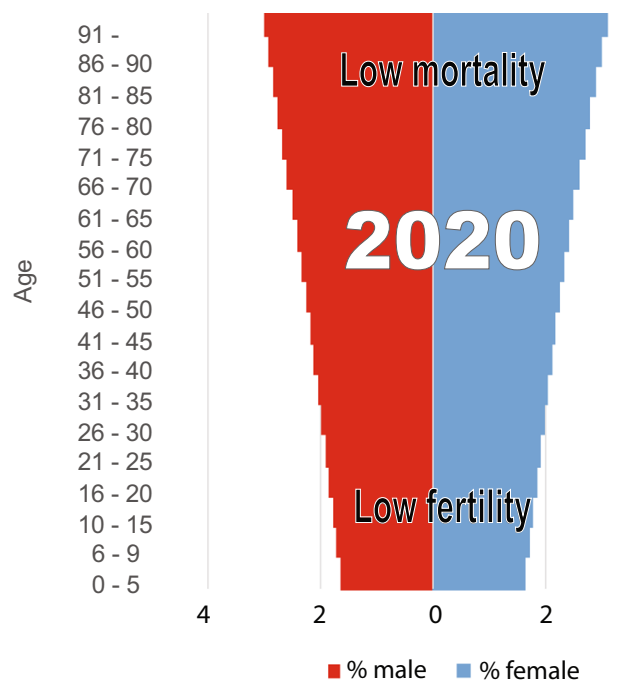

a)

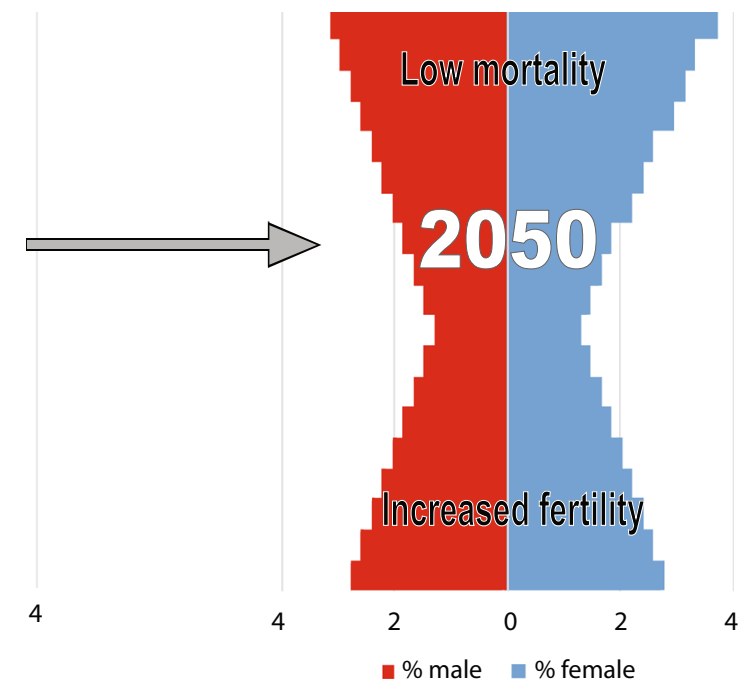

b)

Fig. 6 Stylised population pyramid transition. Note: A stylised representation of a transition from a low mortality and fertility state of a given population, to low mortality and increased fertility state (i.e. vulnerable hourglass).

and economic measures. In some countries there are already discussions about the possibility of a 'depopulation dividend' through interventions such as the above linked to economic revitalization activities, i.e. 'achievement from depopulation of positive gains that contribute to socio-cultural, political-economic, and environmentally sustainable living ${ }^{\prime 109}$ (see example of 'depopulation dividend' for Sado Island in Japan, Supplementary Table 3).

However, it is also worth noting that in many countries mortality rates may not decline substantially further, but fertility rates may further decrease, creating thus a very skewed age pyramid (Fig. 6a). In such cases it is possible that enormous efforts will be put in place through diverse sets of policies to increase fertility rate and/or promote migration ${ }^{110}$. Assuming this is successful, cities (and broader countries) may over time enter a new very vulnerable phase due to the previously skewed age distribution. This new demographic phase we may call the 'vulnerable hour-glass' (Fig. 6b) and would represent further economic and social challenges with a very unfavourable dependency ratio (see the section "Interface of ageing, population shrinking and urbanization").

Even though this transition is hypothetical at the moment, some of its aspects have partly manifested in some urban contexts such as the formerly shrinking and until today also ageing city of Leipzig (see Supplementary Fig. 5 for Leipzig's age pyramid). Some of the successful policy interventions used in Leipzig that might have been causing such types of transitions include the large investments in the housing estates in the inner city, which became further attractive to young adults and middle-aged that moved there due to its affordable urban life, nurseries/day-care facilities, newly equipped universities and high schools, and a certain openness for new ideas Germany ${ }^{111-113}$.

Even though the possibility of this hourglass-type transition and its eventual and long-term outcomes for urban sustainability are poorly understood at the moment, it is important that coordinated actions such as the above should seek to prevent it from manifesting.

\section{CONCLUSIONS}

This Perspective has critically discussed the opportunities and challenges that an ageing and shrinking urban population will have for long-term sustainability, and identified some of the possible emerging intervention to capitalize on the opportunities and reduce the challenges. In particular we find that this demographic transition will have major implications for implementing different SDGs, with some of the most promising emerging interventions including (a) innovations for health care and mobility, (b) improvement of green/public space design and extent, (c) social inclusion through social participation and urban knowledge coproduction. Considering that the underlying mechanisms are highly variable between SDG targets and geographical contexts, there will be a need for combining context-specific policy and practice interventions to both leverage the opportunities and reduce the challenges posed by population ageing and shrinking for sustainability. Considering the quick pace of these changes, especially as the rate of ageing and population shrinking might be underestimated in official statistics, there is a need for urgent action.

\section{DATA AVAILABILITY}

Data referenced in this study are available from World Population Prospects 2019 Revision, United Nations (https://population.un.org/wpp/Download/Standard/ Population $/)^{1}$ and World Urbanization Prospects 2018, United Nations (https:// population.un.org/wup/Download//114.

Received: 25 June 2020; Accepted: 23 January 2021; Published online: 27 May 2021

\section{REFERENCES}

1. UN. Population Dynamics. World Population Dynamics. World Population Prospects 2019 Revision (United Nations, 2019).

2. UN. World Population Ageing 2019: Highlights (United Nations, 2019).

3. De Sherbinin, A., Carr, D., Cassels, S. \& Jiang, L. Population and environment. Annu. Rev. Environ. Resour. 32, 345-373 (2007).

4. UN. Transforming Our World: the 2030 Agenda for Sustainable Development (United Nations, 2015).

5. UN. Ageing, Older Persons and the 2030 Agenda for Sustainable Development (United Nations, 2017).

6. UN-Habitat. Urbanization and development: emerging futures. In UN Habitat World Cities Report 2016 (United Nations Human Settlements Programme, 2016).

7. Harper, S. Economic and social implications of aging societies. Science 346, 587-591 (2014).

8. Götmark, F., Cafaro, P. \& O'Sullivan, J. Aging human populations: good for us, good for the earth. Trends Ecol. Evol. 33, 851-862 (2018). 
9. Haase, D. et al. (eds) The Urban Planet: Patterns and Pathways to the Cities We Want (Cambridge University Press, 2018).

10. Haase, D., Kabisch, N. \& Haase, A. Endless urban growth? On the mismatch of population, household and urban land area growth and its effects on the urban debate. PLOS ONE 8, 1-8 (2013).

11. Wolff, M. \& Wiechmann, T. Urban growth and decline: Europe's shrinking cities in a comparative perspective 1990-2010. Eur. Urban Reg. Stud. 25, 122-139 (2018).

12. Haase, A., Nelle, A. \& Mallach, A. Representing urban shrinkage-The importance of discourse as a frame for understanding conditions and policy. Cities 69, 95-101 (2017).

13. Vollset, S. E. et al. Fertility, mortality, migration, and population scenarios for 195 countries and territories from 2017 to 2100: a forecasting analysis for the Global Burden of Disease Study. LANCET 396, 1285-1306 (2020).

14. Bricker, D. \& Ibbitson, J. Empty Planet: The Shock of Global Population Decline (Brodways Books, 2019).

15. O'Brien, J. Encyclopedia of Gender and Society, Vol. 1 (SAGE Publications, 2008)

16. Nitsche, N. (ed.). The future fertility of highly educated women: the role of educational composition shifts and labor market barriers. Vienna Yearbook Popul. Res. 15, 19-25 (2017).

17. Martine, G., Alves, J. E. \& Cavenaghi, S. Urbanization and Fertility Decline: Cashing in on Structural Change IIED Working Paper (IIED, 2013).

18. Nargund, G. Opinion paper declining birth rate in developed countries: a radica policy re-think is required. Facts Views Vis. ObGyn 1, 191-193 (2009)

19. Casey, B. et al. Opinion Paper Declining Birth Rate in Developed Countries: A Radical Policy Re-think is Required. OECD Economics Department Working Papers 369 (OECD, 2009)

20. Adger et al. Urbanization, migration, and adaptation to climate change. One Earth 3, 396-399 (2020).

21. McLeman, R. A. \& Hunter, L. M. Migration in the context of vulnerability and adaptation to climate change: insights from analogues. Wiley Interdiscip. Rev. Clim. Chang. 1, 450-461 (2010).

22. WHO. World Report on Ageing and Health (World Health Organization, 2015)

23. Luiu, C., Tight, M. \& Burrow, M. Factors preventing the use of alternative transport modes to the car in later life. Sustain. 10,1-21 (2018).

24. UN. Policy Brief: The Impact of COVID-19 on Older Persons (United Nations, 2020)

25. Sanderson, W. C., Scherbov, S. \& Gerland, P. Probabilistic population aging. PLoS ONE 12, 1-12 (2017).

26. OECD. Ageing in Cities (OECD Publishing, 2015).

27. Rockström, J. \& Sukhdev, P. From MDGs to SDGs: Transition to a Development Paradigm of Human Prosperity Within a Safe Operating Space on Earth. Input to the 11th Session of the UN Open Working Group on Sustainable Development Goals, 30 April, 2014 (UN, 2014).

28. IPCC. Climate Change 2014: Synthesis Report. Contribution of Working Groups I, II and III to the Fifth Assessment Report of the Intergovernmental Panel on Climate Change (IPCC, 2015)

29. Brondizio, E. S., Settele, J., Díaz, S. \& Ngo, H. T. (eds) Global Assessment Report On Biodiversity and Ecosystem Services of the Intergovernmental Science-Policy Platform on Biodiversity and Ecosystem Services (IPBES Secretariat, 2019).

30. Pongsiri, M. J., Gatzweiler, F. W., Bassi, A. M., Haines, A. \& Demassieux, F. The need for a systems approach to planetary health. Lancet Planet. Heal. 1, e257-e259 (2017).

31. Haines, A., Harris, F., Kasuga, F. \& Machalaba, C. Future Earth-Linking research on health and environmental sustainability. BMJ 357, j2358 (2017).

32. Zagheni, E. The leverage of demographic dynamics on carbon dioxide emissions: does age structure matter? Demography 48, 371-399 (2011).

33. Wei, T., Zhu, Q. \& Glomsrød, S. How will demographic characteristics of the labor force matter for the global economy and carbon dioxide emissions? Ecol. Econ. 147, 197-207 (2018)

34. Ohashi, H., Fukasawa, K., Ariga, T., Matsui, T. \& Hijioka, Y. High-resolution national land use scenarios under a shrinking population in Japan. Trans. GIS 23, 786-804 (2019).

35. HelpAge International. Climate Change in an Ageing World (HelpAge International, 2015).

36. Tamura, K., Hayashi, H. \& Tatsuki, S. How long-term care insurance system worked for diaster response of the elderly to the Niigata flood and the midNiigata prefecture earthquake. J. Soc. Saf. Sci. 7, 213-220 (2005).

37. Lee, S. \& Vink, K. Assessing the vulnerability of different age groups regarding flood fatalities: case study in the Philippines. Water Policy 17, 1045-1061 (2015).

38. Keysor, J. J. et al. Community environmental factors are associated with disability in older adults with functional limitations: The (MOST) study. J. Gerontol. Ser. A: Biol. Sci. 65A, 393-399 (2010).

39. Wong-Parodi, G. \& Feygina, I. Factors influencing (Mal)adaptive responses to natural disasters: the case of Hurricane Matthew. Weather Clim. Soc. 10, 747-768 (2018).
40. Åström, D. O., Forsberg, B. \& Rocklöv, J. Heat wave impact on morbidity and mortality in the elderly population: a review of recent studies. Maturitas 69 99-105 (2011)

41. Fumiaki, F., Jun, M. \& Hideto, S. Spatial and temporal features of heat stroke mortality in Japan and their relation to temperature variations, 1999-2014. Geogr. Rev. Japan Ser. B 91, 17-27 (2018).

42. O'Neill, B. C. et al. Global demographic trends and future carbon emissions. Proc. Natl. Acad. Sci. USA 107, 17521 LP-17517526 (2010).

43. Kluge, F., Zagheni, E., Loichinger, E. \& Vogt, T. The advantages of demographic change after the wave: fewer and older, but healthier, greener, and more productive? PLOS ONE 9, e108501 (2014).

44. Shigetomi, Y., Nansai, K., Kagawa, S. \& Tohno, S. Changes in the carbon footprint of Japanese households in an aging society. Environ. Sci. Technol. 48, 6069-6080 (2014).

45. Haq, G., Minx, J., Whitelegg, J. \& Owen, A. Greening the Greys: Climate Change and the Over 50s (Stockholm Environment Institute, 2007).

46. Long, Y. et al. Unequal age-based household emission and its monthly variation embodied in energy consumption-a cases study of Tokyo, Japan. Appl. Energy 247, 350-362 (2019).

47. Nansai, K., Fry, J., Malik, A., Takayanagi, W. \& Kondo, N. Resources, Conservation \& recycling carbon footprint of Japanese health care services from 2011 to 2015. Resour. Conserv. Recycl. 152, 104525 (2020).

48. Bloom, M. S., Palumbo, J., Saiyed, N., Lauper, U. \& Lin, S. Food and waterborne disease in the Greater New York City Area following Hurricane Sandy in 2012. Disaster Med. Public Health Prep. 10, 503-511 (2016).

49. WHO. Prevention and Control of Outbreaks of Seasonal Influenza in Long-term Care Facilities: a Review of the Evidence and Best Practice Guidance (World Health Organization, 2017)

50. Government Office for Science. Future of an Ageing Population (Government Office for Science, 2016).

51. Schröder-Butterfill, E. \& Marianti, R. A framework for understanding old-age vulnerabilities. Ageing Soc. 26, 1-22 (2006).

52. ILO. World Social Protection Report 2017-19. Universal social protection to achieve the Sustainable Development Goals. (International Labour Office, Geneva, 2017).

53. Hellmann, T., Schmidt, P. \& Heller, S. M. Social Justice in the EU and OECD: Index Report 2019 (Bertelsmann Stiftung, 2019).

54. Leroux, J., Morrison, K. \& Rosenberg, M. Prevalence and predictors of food insecurity among older people in Canada. Int. J. Environmen. Res. Public Health 15, (2018) https://doi.org/10.3390/ijerph15112511

55. Fernandes, S. G. et al. Food insecurity in older adults: results from the epidemiology of chronic diseases Cohort Study 3. Front. Med. 5, 203 (2018).

56. FAO. Regional Overview of Food Security and Nutrition: Europe and Central Asia (Food and Agriculture Organization, 2018).

57. Marinoudi, V. et al. Robotics and labour in agriculture. A context consideration Biosyst. Eng. 184, 111-121 (2019).

58. Hoekstra, M. S. et al. Shrinkage and housing inequality: policy responses to population decline and class change. J. Urban Aff. 42, 333-350 (2020).

59. Buffel, T., Phillipson, C. \& Rémillard-Boilard, S. Age-friendly cities and communities: new directions for research and policy. In Encyclopedia of Gerontology and Population Aging 1st edn (eds, Gu, D. \& Dupre, E.) (Springr Nature, 2019).

60. Fitzgerald, K. G. \& Caro, F. G. An overview of age-friendly cities and communities around the world. J. Aging Soc. Policy 26, 1-18 (2014).

61. HAPPI. Housing our Ageing Population: Panel for Innovation (DCLG, 2009).

62. IPPR. Innovative Approaches to Joining up Housing and Health (Institute for Public Policy Research, 2014).

63. The Centre for Reviews and Dissemination. Effectiveness Matters: Housing Improvement and Home Safety (University of York, 2014).

64. Kemperman, A. \& Timmermanns, H. Green spaces in the direct living environment and social contacts of the ageing population. Landsc. Urban Plan. 129, 44-54 (2014).

65. Wang, D. \& MacMillan, T. The benefits of gardening for older adults: a systematic review of the literature. Act. Adapt. Aging 37, 153-181 (2013).

66. WHO. Global Age-Friendly Cities Guide (World Health Organization, 2015).

67. Rupprecht, C. D. D. Informal urban green space: Residents' perception, use, and management preferences across four major Japanese shrinking cities. Land $\mathbf{6}$ 59 (2017).

68. Biggs, S. \& Tinker, A. What Makes a City Age-friendly? (Help the Aged, 2007).

69. Ormerod, M. et al. How can Transport Provision and Associated Built Environment Infrastructure be Enhanced and Developed to Support the Mobility Needs of Individuals as they Age (Government Office for Science, 2015)

70. Haga, K. Innovation and entrepreneurship in aging societies: theoretical reflection and a case study from kamikatsu, Japan. J. Innov. Econ. 18, 119-141 (2015).

71. Secondi, L., Principato, L. \& Laureti, T. Household food waste behaviour in EU-27 countries: a multilevel analysis. Food Policy 56, 25-40 (2015). 
72. Abdi, J., Al-hindawi, A., Ng, T. \& Vizcaychipi, M. P. Scoping review on the use of socially assistive robot technology in elderly care. BMJ Open 8, e018815 (2018).

73. Bemelmans, R., Gelderblom, G. J., Jonker, P. \& de Witte, L. Socially assistive robots in elderly care: a systematic review into effects and effectiveness. J. Am. Med. Dir. Assoc. 13, 114-120.e1 (2012).

74. Krick, T., Huter, K. \& Seibert, K. et al. Measuring the effectiveness of digital nursing technologies: development of a comprehensive digital nursing technology outcome framework based on a scoping review. BMC Health Serv. Res. 20, 243 (2020)

75. UITP. Becoming a Real Mobility Provider Combined Mobility: Public Transport in Synergy with Other Modes Like Car-Sharing, Taxi and Cycling (International Association of Public Transport, 2011).

76. Li, Y. \& Voege, T. Mobility as a service (MaaS): challenges of implementation and policy required. J. Transp. Technol. 07, 95-106 (2017).

77. MacArthur, J., Dill, J. \& Person, M. Electric bikes in North America: results of an online survey. Transp. Res. Rec. 2468, 123-130 (2014).

78. Rahman, M. M., Deb, S., Strawderman, L., Smith, B. \& Burch, R. Evaluation of transportation alternatives for aging population in the era of self-driving vehicles. IATSS Res. 44, 30-35 (2020).

79. Bai, X., Nath, I., Hasan, N. \& Jaron, D. Health and wellbeing in the changing urban environment: complex challenges, scientific responses, and the way forward. Curr. Opin. Environ. Sustain. 4, 465-472 (2012).

80. Kuo, M. How might contact with nature promote human health? Promising mechanisms and a possible central pathway. Front. Psychol. 6, 1093 (2015).

81. Gascon, M. et al. Residential green spaces and mortality: a systematic review. Environ. Int. 86, 60-67 (2016)

82. Chao, T. -Y. Planning for Greying Cities: Age-Friendly City Planning and Design Research and Practice (Routledge, 2017).

83. Simpson, D. Young-Old Urban Utopias of an Aging Society (Lars Müller Publishers, 2014).

84. Nefs, M., Alves, S., Zasada, I. \& Haase, D. Shrinking cities as retirement cities? Opportunities for shrinking cities as green living environments for older individuals. Environ. Plan. A 45, 1455-1473 (2013).

85. Wang, X. \& Rodiek, S. Older adults' preference for landscape features along urban park walkways in Nanjing, China. Int. J. Environ. Res. Public Health 16, 3808 (2019).

86. Esther, H. K. et al. satisfaction with planning and design of public parks in high density old districts: an ordered logit model. Landsc. Urban Plan. 165, 39-53 (2017).

87. Tan, Z., Lau, K. K.-L., Roberts, A. C., Chao, S. T.-Y. \& Ng, E. Designing urban green spaces for older adults in Asian cities. Int. J. Environ. Res. Public Health 16, 4423 (2019).

88. Neuman, M. The compact city fallacy. J. Plan. Educ. Res. 25, 11-26 (2005).

89. Yamada, C., Terada, T., Tanaka, T. \& Yokohari, M. Directions for vacant lot management in the outer suburbs of the Tokyo metropolitan region. Urban Reg. Plan. Rev. 3, 66-84 (2016).

90. Tominaga, M. Urban and spatial planning in Japan. Urb. Spat. Plan. Japan 2, 29-36 (2011).

91. Oda, K., Rupprecht, C., Tsuchiya, K. \& McGreevy, S. R. Urban agriculture as a sustainability transition strategy for shrinking cities? Land use change trajectory as an obstacle in Kyoto City, Japan. Sustainability 10, 1048 (2018).

92. Yokohari, M. \& Bolthouse, J. Planning for the slow lane: the need to restore working greenspaces in maturing contexts. Landsc. Urban Plan. 100, 421-424 (2011)

93. Lemonsu, A., Viguié, V., Daniel, M. \& Masson, V. Vulnerability to heat waves: Impact of urban expansion scenarios on urban heat island and heat stress in Paris (France). Urban Clim. 14, 586-605 (2015).

94. Kotulla, T., Denstadli, J. M., Oust, A. \& Beusker, E. What does it take to make the compact city. Liveable for wider groups? Identifying key neighbourhood and dwelling features. Sustainability 11, 3480 (2019).

95. Smith, R. J., Lehning, A. J. \& Kim, K. Aging in place in gentrifying neighborhoods: implications for physical and mental health. Gerontologist 58, 26-35 (2018).

96. Schiano-Phan, R., Weber, F. \& Santamouris, M. The mitigative potential of urban environments and their microclimates. Buildings 5, 783-801 (2015).

97. Birks, F. \& Prater, K. Adapting to global change: ageing. Urban. Resil. Archit. Des. 84, 28-35 (2014).

98. Richard, P., Conard, M., Katz, R., Dahlgren, E. \& Culligan, P. The Potential for Urban Agriculture in New York City Growing Capacity, Food Security, \& Green Infrastructure (Urban Design Lab at the Earth Institute, Columbia University, 2012).

99. Pretzsch, $\mathrm{H}$. et al. Crown size and growing space requirement of common tree species in urban centers, parks, and forests. Urban For. Urban Green. 14, 466-479 (2015).

100. Arnberger, A. et al. Elderly resident's uses of and preferences for urban green spaces during heat periods. Urban For. Urban Green. 21, 102-115 (2017).
101. Baldwin, C., Matthews, T. \& Byrne, J. Planning for older people in a rapidly warming and ageing world: the role of urban greening. Urban Policy Res. 38 , 199-212 (2020).

102. Theorell, T. Psychological Health Effects of Musical Experiences (Springer Netherlands, 2014).

103. Polk, M. (ed). Co-producing Knowledge for Sustainable Cities: Joining Forces for Change (Routledge, 2015).

104. Fumagalli, N. et al. Sustainable Co-Design with Older People: The Case of a Public Restorative Garden in Milan (Italy). Sustainability 12, 3166 (2020).

105. Corrado, A. M., Benjamin-Thomas, T. E., McGrath, C., Hand, C. \& Laliberte Rudman, D. Participatory action research with older adults: a critical interpretive synthesis. Gerontologist 60, e413-e427 (2020).

106. Cinderby, S. et al. Co-designing urban living solutions to improve older people's mobility and well-being. J. Urban Heal. 95, 409-422 (2018).

107. Littlechild, R., Tanner, D. \& Hall, K. Co-research with older people: perspectives on impact. Qual. Soc. Work 14, 18-35 (2014).

108. Buffel, T. Social research and co-production with older people: developing agefriendly communities. J. Aging Stud. 44, 52-60 (2018).

109. Matanle, P. Towards an Asia-Pacific 'depopulation dividend' in the 21st century: regional growth and shrinkage in Japan and New Zealand. Asia-Pacific J. 15, 5018 (2017).

110. Raute, A. Can financial incentives reduce the baby gap? Evidence from a reform in maternity leave benefits. J. Public Econ. 169, 203-222 (2019).

111. Kabisch, N., Haase, D. \& Haase, A. Evolving reurbanisation? Spatio-temporal dynamics as exemplified by the East German City of Leipzig. Urban Stud. 47, 967-990 (2010).

112. Kabisch, N., Haase, D. \& Haase, A. Reurbanisation: a long-term process or a shortterm stage? Popul. Space Place 25, e2266 (2019).

113. Haase, D., Haase, A., Kabisch, S. \& Bischoff, P. Guidelines for the "Perfect Inner City". Discussing the appropriateness of monitoring approaches for reurbanization. Eur. Plan. Stud. 16, 1075-1100 (2008).

114. UN. United Nations Population Division. World Urbanization Prospects: 2018 Revision (United Nations, 2018)

\section{ACKNOWLEDGEMENTS}

Transdisciplinary Initiatives for Global Sustainability (TIGS) and the Alliance for Global Sustainability, The University of Tokyo, and JSPS-STINT international collaborative research (PI: K.T. and T.E.) for financial support to organize the workshop. A.G. and N.D. acknowledge the support of the Japan Science and Technology Agency (JST) and the National Natural Science Foundation of China (NSFC) for project SASSI. A.G. acknowledges the support of the Japan Society for the Promotion of Science (JSPS) for a Grant-In-Aid of Young Scientists (A) (17H05037). G.B.S. would like to acknowledge the International Research Fellow programme of Japan Society for the Promotion of Science.

\section{AUTHOR CONTRIBUTIONS}

M.P.J., T.E., K.F. and A.G. conceived of the presented idea. M.P.J. and T.E. developed the theory. M.P.J. and J.P. worked on data presentation for global patterns, D.H. analysed situation in Europe, N.D. and J.P. analysed citation in China, O.S., R.W., K.F. examined situation in Japan. A.G., M.P.J., K.F., F.K., and K.T. worked on challenges and opportunities for SDGs. S.E., J.G., S.K., T.T., G.B.S., J.P. and M.Y. worked on the interventions and lessons learnt from ageing and shrinking cities. All authors contributed to the final manuscript.

\section{COMPETING INTERESTS}

The authors declare no competing interests.

\section{ADDITIONAL INFORMATION}

Supplementary information The online version contains supplementary material available at https://doi.org/10.1038/s42949-021-00023-z.

Correspondence and requests for materials should be addressed to M.P.J.

Reprints and permission information is available at http://www.nature.com/ reprints

Publisher's note Springer Nature remains neutral with regard to jurisdictional claims in published maps and institutional affiliations. 
Open Access This article is licensed under a Creative Commons Attribution 4.0 International License, which permits use, sharing, adaptation, distribution and reproduction in any medium or format, as long as you give appropriate credit to the original author(s) and the source, provide a link to the Creative Commons license, and indicate if changes were made. The images or other third party material in this article are included in the article's Creative Commons license, unless indicated otherwise in a credit line to the material. If material is not included in the article's Creative Commons license and your intended use is not permitted by statutory regulation or exceeds the permitted use, you will need to obtain permission directly from the copyright holder. To view a copy of this license, visit http://creativecommons. org/licenses/by/4.0/.

(c) The Author(s) 2021 